Japan. J. Med. Sci. Biol., 33, 295-301, 1980

\title{
ANALYSES FOR NEUTRALIZING ACTIVITIES OF IMMUNO- GLOBULIN FRACTIONS IN ANTI-LEPTOSPIRAL HORSE ANTISERUM
}

\author{
Sho OTANI and KiYoto AKAMA \\ The 2nd Department of Bacteriology, National Institute of Health, \\ Shinagawa-ku, Tokyo 141
}

(Received, July 22, 1980. Accepted, October 21, 1980)

\begin{abstract}
SUMMARY: The 7S and 19S fractions isolated from hyperimmunized antileptospiral horse sera by Sephadex G-200 gel filtration and $\gamma$ - and T-globulin fractions from the antisera by starch block electrophoresis were studied for neutralizing (leptospiricidal) activities against infection with Leptospira. The activity was determined by the intracutaneous method with virulent Shibaura Strain of Leptospira interrogans serovar copenhageni. No significant difference in regression coefficient was observed between the neutralization line with the 19S globulin fraction and that with the 7S globulin fraction, whereas a significant difference in the regression coefficient was observed when the $\gamma$ - and $\mathbf{T}$-globulin fractions were compared; the regression coefficient with $\mathrm{T}$-globulin was consistently larger than that with $\gamma$-globulin.
\end{abstract}

\section{INTRODUCTION}

Serotherapeutic horse antiserum products have widely been used for treating patients of Weil's disease in Japan. However, until recently no quantitative method for the potency test of the serum product was established. The intracutaneous (ic) method in guinea pigs proposed by Akama et al. (1975) seemed to be useful for quantitative determination of the leptospiricidal activity of the antiserum. The neutralization curves obtained by the ic method were shown to be linear over a wide range of dilution of the leptospiral suspension, but a parallelism of the neutralization lines constructed with various antiserum preparations were not always proved (Akama et al., 1975). This suggests multiple mechanisms involved in the neutralization and the presence of different leptospiricidal antibodies in the antiserum.

This paper reports that regression coefficient of the neutralization lines may be different depending on immunoglobulin classes and suggests that the discrepancy in the regression coefficient among antiserum preparations may result from the different distribution of the immunoglobulins in the preparations.

大谷 昌・赤真清人 (国立予防衛生研究所細菌第二部) 


\section{Materials ANd Methods}

Strain: Virulent Shibaura strain belonging to Leptospira interrogans serovar copenhageni (Arimitsu et al., 1980) was used.

Animals: Healthy female guinea pigs of Hartley/F colony weighing 450 $500 \mathrm{~g}$ were used for determining the leptospiricidal activity by the ic method, and guinea pigs of about $300 \mathrm{~g}$ served for preparing the leptospiral suspension for challenge.

Antiserum preparations: Three antiserum preparations of horse origin, Lots 1223, 31 and 33, were used as starting materials for fractionation (Akama et al., 1975).

Leptospiral suspension: The leptospiral suspension for challenge, liver emulsion of guinea pigs infected with virulent Shibaura strain, was prepared by the procedure described by Mori et al. (1974).

Fractionation of antiserum: The antiserum preparations were fractionated by two different procedures, gel filtration on Sephadex G-200 and electrophoresis with starch block as a supporting medium. The fractions obtained from Lots 1223 and 31 were identical with the corresponding ones described in the previous paper (Otani et al., 1980); the others were prepared from Lot 33 by the identical procedures. The two fractions obtained by gel filtration were designated as the $19 \mathrm{~S}$ globulin and $7 \mathrm{~S}$ globulin fractions, and the two or three fractions by electrophoresis as the $\gamma^{-}$(for Lots 31 and 33) or the $\gamma_{2^{-}}$and $\gamma_{1^{-}}$ (for Lot 1223) and T-globulin fractions. Each of the fractions obtained by starch block electrophoresis showed a single band when checked by electrophoresis on cellulose acetate membrane.

Determination of the neutralization activity: The antiserum specimen was serially diluted at intervals of 0.125 or 0.25 in logarithm to base 10 . Each of the dilutions was mixed well with an equal volume of each of three dilutions of the leptospiral suspension at intervals of logarithmic 0.75. After incubation at $32 \mathrm{C}$ for $60 \mathrm{~min}, 0.1-\mathrm{ml}$ portions of each mixture were inoculated intracutaneously into the back skin of healthy guinea pigs. Three or more animals were used for each mixture; each animal received 16-20 inoculations. The animals were observed for 7 days for development of hemorrhage at the inoculated sites, and the highest dilution of the serum specimen preventing the development of hemorrhage up to the last day of the observation period was taken as the end point for the leptospiricidal activity. The geometric mean of the end point values was calculated for each of the dilutions of the challenging leptospiral suspension. The results were analyzed statistically.

Cellulose acetate membrane electrophoresis: An amount of $0.01 \mathrm{ml}$ of the serum fraction was placed on cellulose acetate membrane and allowed to migrate

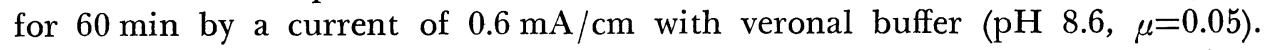
The membrane was stained with Ponseau 3R, immersed into a Decalin solution, and examined densitometrically.

Determination of protein concentration: Protein concentration of the serum 
TABLE I

Neutralization lines with Sephadex G-200 fractions from two antiserum preparations

\begin{tabular}{lrc}
\hline \multicolumn{1}{c}{ Specimen } & $\begin{array}{c}\text { Protein } \\
(\mathrm{mg} / \mathrm{ml})\end{array}$ & Equation $^{1)}$ \\
\hline Lot 1223 & & \\
$\quad$ Parent preparation & 82.86 & $\mathrm{y}=0.50 \mathrm{x}-1.51$ \\
19S globulin & 2.48 & $\mathrm{y}=0.44 \mathrm{x}+0.06$ \\
7S globulin & 6.17 & $\mathrm{y}=0.47 \mathrm{x}-0.45$ \\
Lot 31 & & \\
$\quad$ Parent preparation & 94.46 & $\mathrm{y}=0.55 \mathrm{x}-1.73$ \\
19S globulin & 1.93 & $\mathrm{y}=0.47 \mathrm{x}+0.22$ \\
7S globulin & 13.09 & $\mathrm{y}=0.50 \mathrm{x}-0.99$ \\
\hline
\end{tabular}

1) The equation of the neutralization lines was calculated by the method of least squares.

specimen was estimated by the method of Lowry et al. (1951) with bovine serum albumin as a standard.

\section{RESULTS \\ Neutralization Lines with Sephadex Fractions}

Two parent antiserum preparations, Lots 1223 and 31, and four fractions prepared from them by gel filtration were examined for the neutralization curves. The results are summarized in Table I. Lineality of the lines with all the specimens was not refused; no significant difference was shown among the slopes of the neutralization lines made with the specimens $(p=0.05)$ with the common variance $(0.146)$ estimated from the ranges of the values obtained by 47 similar titrations, in which 141 dilutions of the serum specimens were examined.

\section{Neutralization Lines with Electrophoretic Fractions}

Three parent antiserum preparations were fractionated by starch block electrophoresis. For Lot 1223, three fractions corresponding to $\gamma_{2^{-}}, \gamma_{1^{-}}$and T-globulins were selected and examined for the neutralization lines. Lineality of the lines was confirmed. The results are illustrated in Fig. 1. The slope of the neutralization line constructed with T-globulin differed from those with either parent antiserum or with $\gamma$-globulin fractions. Similar results were obtained with Lots 31 and 33 as shown in Table II.

\section{Parallelism of the Neutralization Lines with the Fractions from Three Parent Antiserum Preparations}

Differences in regression coefficient of the neutralization lines with the frac- 


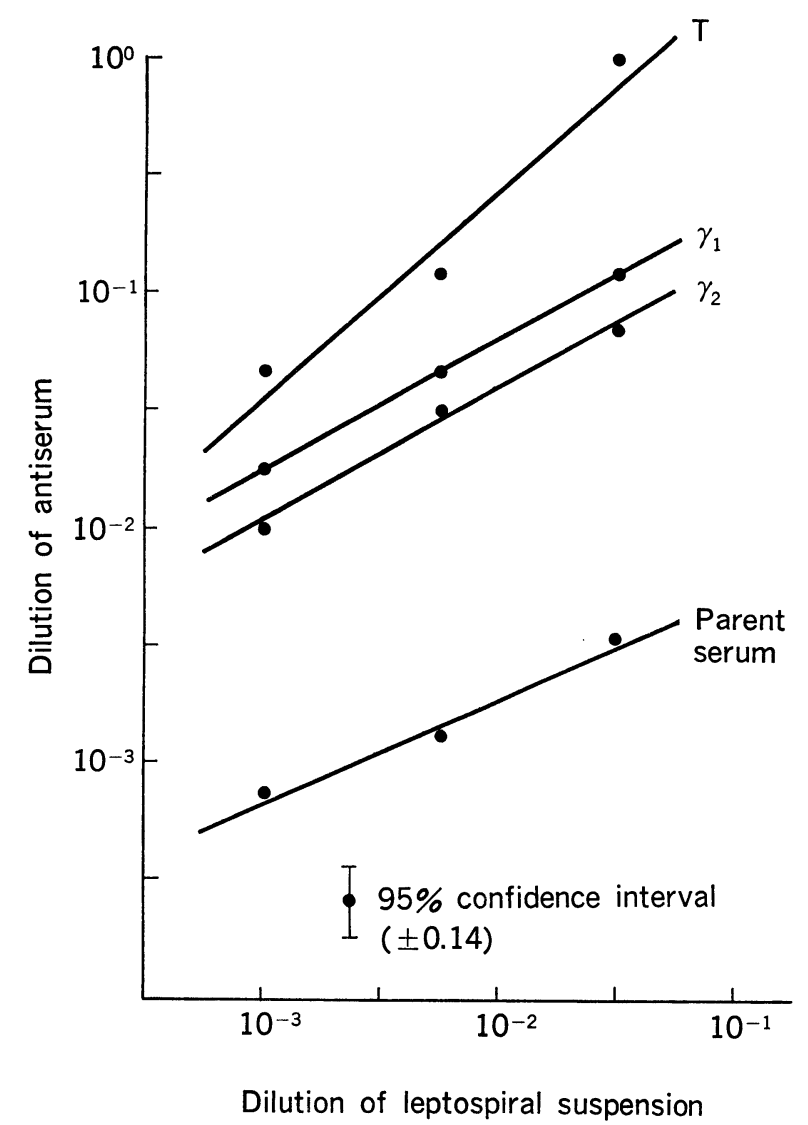

Fig. 1. Neutralization lines with the fractions from Lot 1223 obtained by electrophoresis.

tions from the three antiserum preparations were statistically analyzed. No significant difference $(p=0.05)$ was observed among the coefficients with the parent antisera and their $19 \mathrm{~S}$ and $7 \mathrm{~S}$ globulin fractions. As shown in Table III, no significant difference in regression coefficient was demonstrated among the four $\gamma$-globulin fractions or among the three T-globulin fractions, whereas a significant difference was observed between regression coefficients with $\gamma$-globulin and T-globulin.

\section{Comparison of Neutralizing Activities of Different Immunoglobulins in Parent Antiserum Preparation}

The neutralizing activities of the $7 \mathrm{~S}$ and $19 \mathrm{~S}$ globulin fractions obtained from the same parent antiserum preparation were calculated with the equations for the neutralization lines (Table I) and common slopes for each parent antiserum series ( $\mathrm{b}$ for Lot $1223=0.472$, $\mathrm{b}$ for Lot $31=0.506$ ). The activities of the 
TABLE II

Neutralization lines with electrophoretic fractions from three antiserum preparations

\begin{tabular}{lrl}
\multicolumn{1}{c}{ Specimen } & $\begin{array}{c}\text { Protein } \\
(\mathrm{mg} / \mathrm{ml})\end{array}$ & Equation \\
\hline Lot 1223 & & \\
Parent preparation & 82.86 & $\mathrm{y}=0.44 \mathrm{x}-1.85$ \\
$\gamma_{2}$-globulin & 3.05 & $\mathrm{y}=0.57 \mathrm{x}-0.28$ \\
$\gamma_{1}$-globulin & 1.53 & $\mathrm{y}=0.56 \mathrm{x}-0.08$ \\
T-globulin & 1.45 & $\mathrm{y}=0.89 \mathrm{x}+1.25$ \\
Lot 31 & & \\
Parent preparation & 94.46 & $\mathrm{y}=0.53 \mathrm{x}-1.49$ \\
r-globulin & 5.39 & $\mathrm{y}=0.61 \mathrm{x}-0.63$ \\
T-globulin & 3.87 & $\mathrm{y}=0.89 \mathrm{x}+1.81$ \\
Lot 33 & & \\
Parent preparation & 105.88 & $\mathrm{y}=0.61 \mathrm{x}-1.88$ \\
$\gamma$-globulin & 4.31 & $\mathrm{y}=0.44 \mathrm{x}-1.17$ \\
T-globulin & 3.15 & $\mathrm{y}=0.94 \mathrm{x}+1.06$ \\
\hline
\end{tabular}

\section{TABLE III}

Parallelism among the neutralization lines with $\gamma-$ and $T$-globulin fractions derived from three antiserum preparations

\begin{tabular}{|c|c|c|c|c|c|}
\hline \multirow{3}{*}{$\begin{array}{c}\text { Parent } \\
\text { antiserum }\end{array}$} & \multirow{3}{*}{ Fraction } & \multicolumn{4}{|c|}{ Parent antiserum and fraction } \\
\hline & & \multicolumn{2}{|c|}{ Lot 31} & \multicolumn{2}{|c|}{ Lot 33} \\
\hline & & $r$ & $\mathrm{~T}$ & $r$ & $\mathrm{~T}$ \\
\hline \multirow[t]{3}{*}{ Lot 1223} & $\gamma_{1}$ & + & ** & + & ** \\
\hline & $r_{2}$ & + & ** & + & ** \\
\hline & $\mathbf{T}$ & $*$ & + & $* *$ & + \\
\hline \multirow[t]{2}{*}{ Lot 31} & $\gamma$ & & & + & $* *$ \\
\hline & $\mathbf{T}$ & & & ** & + \\
\hline
\end{tabular}

+ , No significant deviations from parallelism at $p=0.05$

*, Significant deviations from parallelism at $\mathrm{p}=0.05$

**, Significant deviations from parallelism at $\mathrm{p}=0.01$

$7 \mathrm{~S}$ and 19S fractions were compared to each other. The leptospiricidal (neutralizing) activity of the $7 \mathrm{~S}$ fraction was 16.7 times higher than that of the $19 \mathrm{~S}$ fraction for Lot 1223, and 364 times for Lot 31 , on the bases of protein contents of the fractions presented in Table $\mathrm{I}$.

On the other hand, quantitative comparison of the neutralizing activity between $T$ - and $\gamma$-globulins is theoretically impossible because of the difference in regression coefficient of the neutralization lines. 


\section{Discussion}

The antibody activities of immunoglobulins separated from sera of various animals immunized or infected with leptospires were reported by many workers (Hashimoto, 1955; Kikuchi, 1956; Varfolomeyeva et al., 1964; Graves and Faine, 1970; Crawford, 1972; Chiba, 1973; Morris and Hussaini, 1974; Shishkina et al., 1976; Morris et al., 1977; Adler and Faine, 1978; Cinco et al., 1978). However, instructive information is too scanty in the articles to serve for improving the quality of the therapeutic horse antiserum product. Since it was shown that the neutralization lines with various horse antiserum products were not always parallel from one to another (Akama et al., 1975), attempts were made to scrutinize the cause of the disagreement with special reference to immunoglobulin classes.

A significant difference was demonstrated between the slopes of the neutralization lines with the $\gamma$ - and T-globulin fractions, but not between those with the 19S and 7S globulin fractions; no significant difference was shown among the slopes with the three T-globulin fractions of different origins, showing that the T-globulin fractions have larger regression coefficient of the neutralization lines than the $\gamma$-globulin fractions. The difference in regression coefficient of the neutralization lines observed with some antiserum products may be explained by the difference in the active T-globulin contents. Removal of the T-globulin fraction from the therapeutic antiserum product may be helpful in reducing the disagreement in the regression coefficient of the neutralization line. However, since T-globulin might have so-called leptospiral antitoxin, understanding of the roles of the immunoglobulin classes in the therapeutic horse antiserum product should be circumspective.

It remains to be studied whether there is any difference in the mechanisms of inactivating leptospires among the antibodies of different immunoglobulin classes.

\section{Acknowledgement}

This study was supported by a research grant from Pharmaceutical and Supply Bureau, Ministry of Health and Welfare, Japan.

\section{REFERENCES}

Adler, B. and Faine, S. (1978): The antibodies involved in the human immune response to leptospiral infection. J. Med. Microbiol., 11, 387-400.

Akama, K., Otani, S., Mori, M. and Arimitsu, Y. (1975): Studies on the potency test of antiserum for Weil's disease by the intracutaneous method. Japan. J. Med. Sci. Biol., 28, 1-9.

ARImitsu, Y., Mori, M. AND AKama, K. (1980): Cross antigenicities of Leptospira interrongans serovar copenhageni Shibaura strain for preparing biological products in Japan. Japan. J. Med. Sci. Biol., 33, 223-229.

Cinco, M., Dougan, R. And Panfili, E. (1978): The immunoglobulins response in rabbit to single antigenic factors of Leptospira. Investigations with two serovars from saprophytic 
Leptospira. Zbl. Bakt. Hyg., I. Abt. Orig. A 242, 85-92.

Chiba, K. (1973): Purification and lyophylization of Weil's disease therapeutic serum. Kitasato Arch. Exptl. Med., 46, 57-71.

CRAWFORD, R. P. (1972): Identification of the immunoglobulins in serum of guinea pigs infected with serogroup Pomona Leptospires. Amer. J. Vet. Res., 33, 2289-2298.

Graves, S. AND FaINe, S. (1970): Antileptospiral agglutinins produced in rabbits. Bull. W.H.O., $43,579-587$.

Hashimoto, T. (1955): Studies on the Weil's antiserum. Japan. J. Bacteriol., 10, 893-895 (text in Japanese).

KIKUCHI, K. (1956): Studies on the purification of antileptospiral horse sera. Japan. J. Bacteriol., $11,709-717$ (text in Japanese).

Lowry, O. H., Rosebrough, N. J., Farr, A. L. and Randall, R. J. (1951): Protein measurement with the Folin phenol reagent. J. Biol. Chem., 193, 265-275.

Mori, M., Arimitsu, Y., OTAni, S. AND AKama, K. (1975): Intracutaneous infection with Leptospira icterohaemorrhagiae (Shibaura strain) of the guinea pig. Japan. J. Med. Sci. Biol., 27, 297-308.

Morris, J. A. AND Hussaini, S. N. (1974): Characterization of the antibodies detected by the microscopic agglutination test for bovine leptospirosis. J. Hyg., Camb., 73, 425-432.

Morris, J. A., Gill, J. E. AND Hussaini, S. N. (1977): An examination of the antibodies active in the indirect haemagglutination test for bovine leptospirosis. Brit. Vet. J., 133, 17-24.

Otani, S., Arimitsu, Y. And Akama, K. (1980): Antibody activities of immunoglobulins in antileptorpiral horse sera. Japan. J. Med. Sci. Biol., 33, 239-247.

Shishkina, Z. S., Baryshev, P. M., Chernukha, Yu. G. ANd Kokovin, I. L. (1976): Formation of antibodies and immunoglobulins of various classes in persons vaccinated with warm antileptospirosis polyvalent vaccine. Zbl. Bakt. Hyg., I. Abt. Orig. A236, 344-353. 